\title{
A Journey Gone Wrong: Mass in the Thorax
}

\author{
Chong SL \\ Pediatric Medicine, KK Women's and Children's Hospital, Singapore
}

\section{HISTORY}

Two-month old baby boy presented with one-month history of cough to our hospital. His parents are non-consanguineous. He was born full term via normal vaginal delivery with no complication. He remained well after discharge from the hospital but started to have fever, cough and running nose associated with shortness of breath about one month prior to current presentation. He was admitted to a local hospital and diagnosed to have acute bronchiolitis. He received standard treatment according to the local guidelines. The fever and running nose resolved, and he was discharged after few days.

However, his cough persisted. The cough was not associated with milk intake or any noisy breathing. There was no shortness of breath or hoarseness of voice. He had no history of vomiting or cyanosis. The cough was not worse at any particular time of the day. He has no family history of asthma, eczema or allergic rhinitis.

Physical examination revealed a happy, well thrived baby boy who was centrally pink and not in respiratory distress. There was no audible stridor or wheeze. There were bilateral occasional crepitations with end expiratory rhonchi. Systemic examination was otherwise unremarkable.

Full blood count and renal profile were within the normal limit for his age. His nasal pharyngeal aspirates were negative for respiratory viruses' antigen and tested negative for Chlamydia and Bordetella Pertussis. A Chest X-ray was performed followed by a computer tomography of the thorax (pictures).

\section{Corresponding author:}

Chong Siew Le, MRCPCH (UK)

Pediatric Medicine

KK Women's and Children's Hospital

100 Bukit Timah Road

Singapore 229899

Tel No: $+65-62931139$

Fax Number 63941973

E-mail: siew_le@yahoo.com
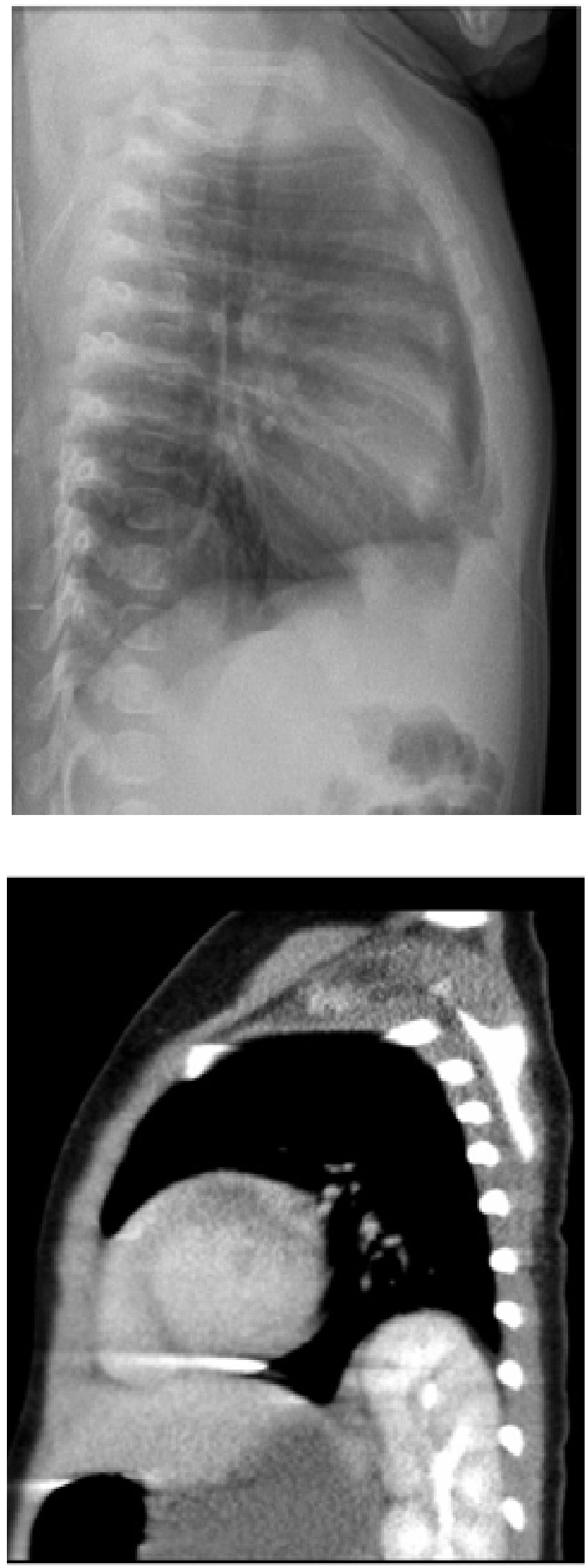


\section{Questions:}

1. What is the diagnosis?
A. Neurogenic tumour.
B. Enlarged spleen.
C. Diaphragmatic hernia with bowel lobes.
D. Intrathoracic kidney.
E. Esophageal achalasia.

2. What is the treatment?
A. 3 monthly renal profile because renal failure is common.
B. Total nephrectomy to prevent malig nant change.
C. Biopsy to rule out malignancy.
D. Yearly intravenous urogram.
E. Monitor clinically with no special treatment.

\section{Answer: D, E}

The above CT scan thorax with contrast showed an intrathoracic kidney with contrast filling its pelvocalyceal system. Intrathoracic kidney is a rare form of ectopic kidney with a prevalence of less than $1 / 10,000$ cases. ${ }^{1}$ There are four different groups of intrathoracic kidney: 1) thoracic renal ectopia with closed diaphragm; (2) eventration of the diaphragm; (3) diaphragmatic hernia (4) traumatic rupture of the diaphragm. ${ }^{2}$ Most patients, including our patient are in group 1 or 2 , which require no treatment. Patients in group three and four may require urgent surgical intervention to alleviate respiratory or gastrointestinal symptoms or as a measure to prevent strangulation of the herniated organ.

Although benign, there were cases reported on intrathoracic kidney complicated by ureteropelvic junction obstruction, renal cell carcinoma and renal stone, which may warrant clinical monitoring. ${ }^{3-5}$

\section{REFERENCES:}

1. Kageyama $\mathrm{Y}$, Khhara K, Oshima $\mathrm{H}$.

Intratho-racic herniation of the kidney.

Urology 2000;55:143-4.

2. Rattan KN, Rohilla S, Narang R, et al.

Thoracic kidney associated with congenital diaphragmatic hernia. Congenit Anom 2009; 49:118-20.

3. Hampton L, Borden T. Ureteropelvic junction obstruction in a thoracic kidney treated by dismembered pyeloplasty. Urology:2002; 60:164.

4. Kubricht WS 3rd, Henderson RJ, Bundrick WS, Venable DD, Eastham JA. Renal cell carcinoma in an intrathoracic kidney: radiographic findings and surgical considerations. South Med J 1999;92:628.

5. Singh P, Vijjan V, Gupta M, Dubey D, Srivas tava A. Percutaneous nephrolithotomy of a staghorn stone in thoracic ectopic kidney. 